\title{
Education and the Fourth Industrial Revolution: Lessons from COVID-19
}

\author{
Hussien Mohamad Alakrash and Norizan Abdul Razak \\ Faculty of Social Sciences and Humanities, School of Language Studies and Linguistics, Universiti Kebangsaan, Malaysia \\ *Corresponding Author: Norizan Abdul Razak. Email: norjef@ukm.edu.my \\ Received: 11 November 2020; Accepted: 03 May 2021
}

\begin{abstract}
The COVID-19 pandemic has prompted educators to rethink educational practices, especially with regard to technology. The COVID-19 pandemic is a huge challenge to education systems around the world. This Viewpoint offers guidance to teachers, institutional heads, and officials on addressing the crisis. This study investigated technology use in teaching during the COVID-19 lockdown in Malaysia, focusing on technology-based teaching methods, modifications necessitated by this new teaching style, and challenges teachers faced when using technology. Using purposive sampling, a qualitative study was undertaken with a sample of 10 English language teachers from Arabic schools in Malaysia. The results indicated that a digital leap occurred in education during the COVID-19 lockdown because teachers had to quickly adapt to a more technology-based teaching style. The challenges teachers faced included managing virtual classes, ensuring reliable Internet connections, overcoming a lack of preparedness and low digital competence, and dealing with students' mental health. Such changes in teaching methods have created new roles for teachers while also increasing their acceptance of e-learning and remote learning. The contribution of this research is to provide a holistic picture of remote education activities during the pandemic period to establish a linkage between the online teaching-learning process during the COVID-19 outbreak as to ensure the resumption of teaching-learning education as a normal course of procedure in the education system. Despite the human suffering brought by the pandemic, the new norms of education during COVID-19 generally have some pockets of excellence to drive the education into the Fourth Industrial Revolution.
\end{abstract}

Keywords: COVID-19; digital technology; English education; fourth industrial revolution; Education 4.0

\section{Introduction}

With the emergence of the Fourth Industrial Revolution (4IR), rapid developments in science and technology have greatly affected everyday life. In the education sector, developments such as the Internet of Things (IoT) have influenced curricula and introduced educators to new teaching methods. In this context, 4IR is expected to actualize smart education environments that can improve the quality and accessibility of education. However, with the outbreak of COVID-19,

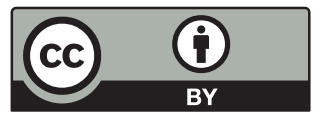

This work is licensed under a Creative Commons Attribution 4.0 International License, which permits unrestricted use, distribution, and reproduction in any medium, provided the original work is properly cited. 
educators had to adjust to such 4IR-based approaches more rapidly than expected. Learning during the pandemic has been largely conducted online, including approaches such as blended learning, project-based learning, and flipped classrooms.

COVID-19 has posed great challenges for education [1]. Educators and parents were largely unprepared and have had to quickly adapt to the "new normal" of online education. About 1.5 billion students around the globe have utilized remote learning during the pandemic [2]. Education 4.0, which refers to technology-based, digitized teaching and learning, fits neatly with these new teaching and learning requirements. COVID-19 has thus presented an opportunity to embrace and adapt to new 4IR-based approaches and leapfrog current educational practices $[3,4]$.

In Malaysia, as in much of the rest of the world, schools and universities were closed in response to COVID-19, necessitating the adoption of remote learning. If used effectively, such remote-learning models can have great potential [5,6]. Even before COVID-19, Malaysia's Ministry of Education recognized the need for changes in response to Education 4.0, including adapting to new learning environments and utilizing new technologies [7]. Such changes have posed challenges for educational institutions in Malaysia as the country works to transform itself into a developed nation [8]. These challenges include limited and inefficient educational resources, outdated teaching styles, inadequate infrastructure, and a lack of close linkages among educational institutions [9].

Despite the current need for innovation in teaching and learning [10,11], it is hampered by outdated policies and limited infrastructure in developing countries. COVID-19 has highlighted the problem of the digital divide in education and the lack of digital infrastructure and access in many societies, especially those where Internet penetration is low. In such regions, digital infrastructure can be especially helpful for advancing education in remote areas [12].

\subsection{IR and Education}

The features of 4IR include "cyber-physical systems, big data, automation, data exchanges, cloud, robots, artificial intelligence and IoT, and (semi-) autonomous industrial techniques" [13]. A consequence of 4IR is "the blurring of technology into every part of our lives," which "is becoming the norm" [14] and is "crashing into our personal and professional lives like a ton of bricks" [15]. It is clear that 4IR is having significant effects on educational processes [16]. Since education under 4IR is propelled by innovation, there is a need to prepare students to be creative and innovative in their thinking.

It is suggested that Education 4.0 will affect the cognitive, affective, and psychomotor domains of learning [17]. Students will need to be competent in digital applications and will thus require appropriate training [18]. Human-machine convergence under 4IR may bridge the disciplinary divides between social sciences, humanities, science, and technology; this can include the specific convergence of disciplines such as computer science, business administration, and mechanical engineering. Universities thus need to collaborate with industry to create new disciplinary programs [19]. Big data, mobile computing, social networks, and clouds allow for self-learning environments, independent of time and place. Students can therefore design their own education pathways according to their personal goals. These new learning approaches require developing skills in areas such as mobile/virtual learning, MOOCs, remote/virtual labs, and gamification [20]. The rising level of complexity in Education 4.0 creates a need for the increased use of blended learning, problem-based learning, and open-source innovations [21].

Education 4.0 requires adjusting traditional curricula to make them more IoT friendly. This calls for an increased emphasis on skills such as critical thinking, problem solving, communication, 
collaboration, and innovative thinking. Specifically, critical thinking and problem-solving skills involve the ability to understand a problem and search for relevant information so that various perspectives can be explored. Meanwhile, communication and collaboration skills are essential information technology-based abilities [22]. Finally, innovative thinking is crucial in the 4IR era with the ongoing convergence of humans and technology. To this end, teachers need to find ways to spur students to think creatively and innovatively. Additionally, since 4IR requires strong digital and data literacy, developing such literacy among students is critical. This requires teachers to use information and communications technology to support learning [23].

\subsection{Virtual Learning Environments}

In virtual learning environments (VLEs), the Internet is used to support traditional classroom teaching [24]. A VLE is a self-contained web-based system that does not require the use of additional technologies. VLEs incorporate text, video, audio, and animation in multimedia environments [25]. In online teaching, teachers can post tasks or course materials to be accessed by students. Moreover, various methods can be used for student assessment. One study examined Saudi female postgraduate students' perceptions of virtual language classes; the results showed positive responses as well as a positive effect on speaking competency [26]. Meanwhile, a study in Jordan evaluated virtual courses from the teachers' perspective; it was found that teachers were better able to use technology for students' receptive skills (e.g., listening and reading) than for their productive skills (e.g., speaking and writing) [27,28]. Other studies have found that students encounter various technical difficulties when learning using technology [29,30].

\section{Method}

This study adopted a qualitative research design and used semi-structured interviews to collect data. The participants were 10 English language teachers from 10 Arabic schools in Malaysia. The teachers were selected based on purposive sampling according to the criteria in Teddlie and $\mathrm{Yu}$ (2007). The specific criteria for participant selection included (1) having experience using technology to teach courses to students and (2) being perceived by their institutions or communities as ICT experts. The interview protocol included six semi-structured questions that focused on new technology-based teaching styles and methods used during the COVID-19 lockdown. The questions were as follows:

(1) Has the Movement Control Order (MCO) in Malaysia affected your teaching style and pedagogy?

(2) If so, how have you used technology to teach during the MCO?

(3) What are the general issues and challenges associated with the use of technology in teaching?

(4) What specific challenges do you face when using technology to teach?

(5) How have you modified your teaching practice to adapt to technology?

(6) What challenges do your students face when you teach online?

\subsection{Procedures}

The researchers were unable to conduct in-person interviews because of the governmentmandated MCO. Therefore, interviews were held using Zoom during the academic session from April to June 2020. The researchers sent the questions to the participants before the interviews so they could familiarize themselves with them. All ethical requirements from the schools were 
adhered to during the study process. The researchers transcribed the interview responses and analyzed the data using inductive thematic analysis.

\section{Results}

This study aimed to investigate new forms of teaching adopted in response to these changes.

\subsection{Effects of Lockdown on Teaching}

All respondents agreed that the lockdown affected how they teach their students. Some, however, supported the new form of teaching while others rejected it.

The shift to remote learning has changed me as a lecturer. I can wholeheartedly say the change has been, and will be, for the better. This shift has required me to use innovation and creativity for the most critical assessments while highlighting the importance of the teacher-student relationship. I will never again take for granted students showing up for class early to tell me about their weekend or students sitting in the back of the room trying to stay under the radar because they are having a bad day.

This response highlights the difficulty of maintaining teacher-student relationships in the new remote classroom environment. However, online teaching has also enabled students to collaborate more than in the traditional classroom.

Despite the difficulties I face in the transition to distance teaching, it has greatly enhanced my relationships with students. I have been trying to integrate innovative elements to differentiate my teaching style. Although Zoom has some limitations, I still prefer to use it for my lectures. Private rooms help boost collaboration among students and enable me to have one-on-one meetings with students who are struggling.

Although some teachers had used technology in their pre-pandemic teaching, the current situation has been a new experience for them, bringing about massive changes in their teaching styles.

Even though I had frequently utilized various ICT devices in teaching, this shift has forced me to think outside the box and use new technologies I had not previously used. Distance learning has helped me to become a more well-rounded teacher and has shown me the extreme difficulties students may face in their learning.

Distance learning has changed my teaching delivery but not my practice. We should be flexible and prepared for changes such as those happening now. The positive aspect of this shift, for me, is that I am rapidly embracing and learning how to integrate new technologies that I did not use before.

Some respondents said that teaching online changed not only the way they deliver their lessons but also their practice. They believed they needed to be flexible and prepared for change. Some felt the shift to online learning had resulted in a positive change since they had to rapidly learn to embrace technology. Moreover, some learned how to integrate new technologies they had never used before in their teaching. Some respondents also believed the shift to online teaching improved their teaching style and prompted them to be more innovative to ensure their students had access to learning. 
Remote learning is making me a better instructor. I've been trying to be innovative as this shift demands innovative ways of teaching. During the lockdown, I was able to design learning materials and upload them to online platforms to be available to students anywhere, anytime. That is a new experience for me.

However, the sudden shift left some teachers feeling confused as they had to quickly modify their whole teaching process. They found the situation challenging because they wanted to ensure their students could continue to learn.

It's actually confusing. I still can't figure out if it's for the better or the worse. I'm facing difficulties in delivering and fulfilling my purpose as the connective piece for my students' access to learning opportunities. It's very difficult to find solutions for the unique needs of students at this unprecedented time.

Nevertheless, most respondents agreed that the technological transformation of teachingEven in a short period of time-Has improved teaching processes considering the emergence of Education 4.0. Many believed that COVID-19 has thus had a leapfrog effect in terms of transitioning to Education 4.0.

\subsection{Teaching Styles during Lockdown}

All respondents said the MCO had caused education to undergo a massive "migration" from traditional learning to remote learning; teachers have had to change their teaching styles in response. It has been suggested that e-learning is effective because it gives students more flexibility in learning and time management. The respondents believed e-learning was the best substitute for in-class teaching during the MCO.

Online learning is the best solution for minimizing the impact of the MCO on education.

And because of the MCO, teachers have an opportunity to fully focus on trying out teaching using ICT tools and customizing their teaching materials and assessments to suit the new approach.

Remote learning requires teaching materials to be designed differently. Instructors might also need to provide technical support to students. However, the suddenness of the lockdown meant most teachers were unprepared for online learning, giving rise to numerous challenges. In this regard, the respondents mentioned adopting several strategies to suit the new instructional style. They also mentioned a need for emergency-preparedness plans to deal with unexpected problems in online teaching. Additionally, many respondents said that students showed a weak tendency toward remote learning, which greatly reduced learning effectiveness. To deal with this, respondents suggested that lessons and teaching materials need to be divided into smaller units to help students focus.

With all courses moving online, the computer servers might not be able to host such a large number of new users, and the online platform might often shut down because of overload. To solve these kinds of unexpected issues, faculty need to prepare a Plan B or even Plan $\mathrm{C}$ before classes begin and inform students in advance.

To ensure that students focus during online classes, instructors should adopt a modular teaching style and divide the teaching material content into different and smaller units. To ensure a clear knowledge structure in the curriculum, each class should last approximately half an hour. 
In traditional classrooms, teachers may use facial expressions or body language to deliver information. In remote learning, however, teachers might not always be visible to students because of limited equipment (no webcam) or unstable Internet connections. Even hearing the teacher's voice can also depend on Internet stability. Therefore, in online teaching, teachers may need to speak more slowly so students can capture the key points. The respondents highlighted the importance of online support from mentors and teaching assistants after class. Such support can be provided using various technologies (e.g., email or social media) according to each student's situation and needs. The respondents felt that for inexperienced teachers, remote teaching involves far greater requirements than traditional teaching.

Faculty should fully communicate with teaching assistants before class to make sure they understand the objectives, knowledge framework, and teaching activities of each class. In this way, teaching assistants can provide effective support in online teaching. Teaching assistants can also provide consultations and answer questions for academically underprepared students using email, WeChat, or other social platforms after class.

The respondents said that, compared to the traditional classroom, teachers have less control in remote learning. Respondents suggested, therefore, that teachers use new techniques to modify homework into activities that will help strengthen students' active and independent learning.

In remote learning, students are more likely to "skip class." Therefore, the progress of online teaching and its learning effectiveness largely depend on students having a high level of active learning outside of class.

The respondents recommended high-impact teaching practices for more effective remote learning. The first principle concerned content. The length, difficulty, and quantity of learning materials should match the behavioral characteristics and academic readiness of students. The second principle pertains to effective delivery. Studies have indicated that students suffer from low concentration when studying remotely or online. Therefore, to achieve effective delivery, teaching speed should be adjusted. The third principle concerns support; namely, students should receive guidance and feedback after an online class. The fourth principle is related to high-quality participation. Measures are needed to improve the degree and depth of student participation in online classes. The fifth and final principle concerns contingency plans. Remote learning demands that teachers prepare contingency plans to address issues that might arise because of problems such as Internet traffic overload or equipment malfunction.

\subsection{Ways of Using Technology in Teaching during Lockdown}

All respondents used online teaching applications and social media platforms to cope with the sudden transition to remote learning. They relied heavily on applications such as Zoom, Google Classroom, Telegram, Free Conference, and WhatsApp. They mainly used these applications because they helped them communicate more effectively with students during the pandemic. Some also felt that online learning could complement traditional teaching, and many intended to continue using online technologies after COVID-19. Respondents further said they used the applications to stay up to date on new innovations in digital technologies. The respondents are knowledgeable about technology but still wanted to stay abreast of innovations, even after the pandemic, since the field is moving toward Education 4.0. 
I have changed how I teach. I use Zoom, which enables me to reach out to my students more efficiently and effectively through chat groups, video meetings, polling, and document sharing. My students also find it easier to communicate on Zoom. I will stick to Zoom even after COVID-19. I believe traditional offline learning and e-learning can go hand in hand.

\subsection{Challenges of Using Technology in Teaching}

Obstacles to fully implementing Education 4.0 include uneven infrastructure, people's attitudes, and the difficulties currently posed by COVID-19. While there is policy support in the education sector, there is also a need for more enthusiasm. One challenge mentioned by respondents was that, unlike being in a physical classroom, it was hard for them to tell if students are paying attention. The respondents mainly attributed this challenge to unreliable Internet.

I would say the biggest challenge of online teaching is ensuring that all my students have equal access to my web-based learning material.

Respondents mentioned that some students had limited access to the Internet or to ICT devices, especially in underserved areas where students might have had to share their parents' phones or computers to attend class. The respondents said they compiled voice notes using WhatsApp or called students with limited computer or Internet access for one-on-one lectures. Such practices helped ensure all students had access to learning materials and could progress in their learning. Meanwhile, a lack of digital competency among some teachers also posed challenges for them.

I think I need to work and enhance my digital literacy. I'm not used to technologyenhanced environments, so I have a lot to learn about technology-based teaching. I haven't had a chance to attend tutorials or courses to improve my digital skills yet. Training programs and workshops should be conducted for improving EFL/ESL teachers' digital competency.

By contrast, some respondents argued that digital competency might not be a priority since there are many other types of literacy they need to cope with remote teaching.

I admit my digital competency level is not high, though it is still acceptable. Yet, I think there are many other literacies that are more important than computer literacy.

Some respondents noted the mental stress experienced by students, teachers, and parents as a result of the lockdown, which they believed could affect remote learning.

While educators scramble to set up "home schools," it is necessary to realize that a stressed mental state is not productive for teaching or learning. Educators, parents, and students need to focus first on adjusting to new routines and environments, which will take time. Lacking a clear sense of when emergency home schooling will end, we should focus first and foremost on our safety and well-being.

The respondents believed that students' utilization of digital technologies for learning was limited and infrequent. This suggests that more awareness-increasing activities and measures should be taken to prepare students for the meaningful use of technology. Moreover, motivating students to use ICT could help increase their engagement so they can use various technologies for educational purposes. 


\subsection{Modifications Made in Response to Technology-Based Teaching}

Remote teaching during lockdown has necessitated drastic changes in teaching and learning processes. Respondents suggested that new ways of teaching should be considered to cope with the sudden changes and that teachers should be creative in devising new methods for effective online learning.

Teachers in this situation should think outside the box to create new learning environments where students can participate, interact, and think in remote learning.

The respondents noted that students found remote learning challenging since it was new to them. Many students needed to modify their schedules to attend remote classes. Respondents also explained that they needed to trust their students and encourage them to engage in self-directed learning. Students, in turn, need to be internally motivated to cope with remote learning.

Teachers around the world are designing meaningful resources; the concepts of school and learning are being reinvented.

I am hopeful this crisis will show everyone the importance of moving learning experiences beyond the traditional school building and school hours, resulting in the more real-world application of content and increasing the frequency of authentic experiences for students.

This new form of teaching has also created new roles for teachers, wherein they need to be facilitators for students, not just instructors. Remote learning grants students more control over their learning. Students who are fast learners can get more work done while those who are slower can review lectures as needed to improve their understanding. Teachers can have more one-onone conversations with students, especially weaker students, to help them become more engaged. In this way, COVID-19 could help foster a greater appreciation for and acceptance of remote learning. As teachers and students spend more time in virtual classes, there is the possibility of recognizing the advantages of distance learning, along with efforts to improve access to technology and the Internet.

As institutions aim to inform and reassure parents and students, they should also focus on enhancing the remote-teaching knowledge of teaching staff since teachers do not have much time to educate themselves. That said, priority should be given to supporting students to make sure their learning continues. Therefore, for teachers who are accustomed to traditional classrooms, it is best for them to use remote-learning applications that are familiar to them or less complicated to learn. Moreover, online learning gives teachers the ability to prepare materials to suit individual students' needs and enable them to study at their own pace. Teachers can also make online appointments with students who need more support or assistance. Such characteristics of remote learning give teachers and students more flexibility in the education process.

\section{Discussion}

COVID-19 has created many challenges for education. Differences in access to technology and parental involvement have exacerbated inequalities. Yet, this situation also provides an opportunity to improve education. That said, maintaining students' and parents' mental and physical wellbeing is just as important. In the absence of face-to-face interaction, applications such as Zoom, WhatsApp, and Facebook, as well as various forums and blogs, have become particularly relevant. These are being increasingly used in education to support remote learning. However, the rapid migration to online teaching has given rise to anxieties and concerns among students and teachers 
as many are unfamiliar with remote learning. Thus, ways to mitigate such feelings are needed to support effective online learning.

Though no single solution can be easily applied to every educational system, various solutions could be combined to create new and effective educational approaches. That said, regardless of specific solutions, remote learning inevitably requires teachers to make effective use of technology. Teachers must therefore identify effective models and methods for implementing technology, along with effective training and planning. Moreover, there is a need to fully grasp the benefits of utilizing technology in teaching. Academic institutions should therefore take the disruptions caused by COVID-19 as an opportunity to harness technology and promote new skills among students, such as adaptability, creativity, critical thinking, innovation, and collaboration. Moreover, traditional education has lost some of its relevance as it has failed to meet the demands of the job market. Thus, technology can potentially help students to become better prepared for the future job market.

With technological advancements, simple elements of traditional classrooms can be easily automated and digitized. In this regard, policymakers need to think about how to use artificial intelligence as a complement to humans, not a substitute for them. Yet, it should be emphasized that remote education cannot be a long-term substitute for traditional classroom education because of the various impediments to the uptake of remote education. Limited ICT infrastructure as well as cultural and socioeconomic factors have contributed to the digital divide in countries such as Malaysia. Thus, although new innovations during the pandemic have helped advance education, there is also the potential to aggravate existing inequalities in developing countries, which already face barriers in access to technology and education.

The relationship between teachers and parents is considered a key factor in the success of education. The pandemic has helped enhance this relationship because of the new roles parents have to play in their children's learning. Further, COVID-19 has given teachers even more opportunities to cooperate, identify solutions, and develop creative teaching methods to overcome the limitations of physical separation. Moreover, educational organizations have offered various solutions and tools to help support students and teachers in their online learning processes.

The concepts of the teacher-centered classroom and the teacher as knowledge holder do not fit the new model of education. Since students can access learning materials anywhere, anytime through various technologies, there is a need to recalibrate teachers' roles. This implies a new role for teachers as facilitators of students' development. The current situation can serve as a disruption to stimulate thinking about new education models and raise the question of how students should be taught to prepare them for twenty-first century skills and requirements. By the time institutions return to traditional face-to-face teaching, the special arrangements and procedures undertaken during the pandemic will likely have had enduring effects. Remote learning in higher education is likely to accelerate as institutions may decide to continue with technologyenhanced learning. For many institutions, the mechanisms put into place in response to COVID-19 may have indeed produced certain benefits.

\section{Conclusion}

Despite the innovative educational solutions developed in response to COVID-19, there remains a gap in our understanding of the best solutions for developing areas where technology access is limited. Policymakers need to take measures to improve Internet infrastructure and learners' access to online platforms, promote the use of digital technologies for remote education, 
and support instructors' ability to work in new environments. There is also a need to provide digital skills development and career guidance for students and improve the education system in terms of technology-based teaching and learning.

This study investigated new forms of teaching during the COVID-19 pandemic. Data collected from $10 \mathrm{EFL}$ teachers at Arabic schools in Malaysia showed that the pandemic greatly affected the whole education sector. New innovative teaching methods were utilized by teachers to cope with the lockdown. Challenges teachers and students faced included a lack of reliable Internet connections, limited access to ICT devices, and limited technological knowledge.

This study has some limitations. It has relatively few participants; this mainly had to do with the timing of the data collection, which coincided with the MCO being imposed throughout the country. This limits the generalizability and representativeness of the results. However, the researchers aimed to overcome this limitation by purposively selecting 10 EFL teachers to enhance data credibility. Future research can include a larger sample of participants.

Acknowledgement: We thank LetPub (www.letpub.com) for its proofing assistance during the preparation of this manuscript.

Funding Statement: This research received funding from the Ministry of Higher Education, Malaysia, under the project "Modeling of B40 Women Entrepreneurs for Economic Wellbeing in the Digital Economy System.”

Conflict of Interests: The authors declare that they have no conflicts of interest to report regarding the present study.

\section{References}

[1] A. E. Al Lily, A. F. Ismail, F. M. Abunasser and R. H. A. Alqahtani, "Distance education as a response to pandemics: Coronavirus and Arab culture," Technology in Society, vol. 63, pp. 1-21, 2020.

[2] G. Basilaia and D. Kvavadze, "Transition to online education in schools during a SARS-CoV-2 coronavirus (COVID-19) pandemic in Georgia," Pedagogical Research, vol. 5, no. 4, pp. 1-9, 2020.

[3] M. Tzifopoulos, "In the shadow of coronavirus: Distance education and digital literacy skills in Greece," International Journal of Social Science and Technology, vol. 5, no. 2, pp. 1-14, 2020.

[4] L. Sun, Y. Tang and W. Zuo, "Coronavirus pushes education online," Nature Materials, vol. 19, no. 6, pp. 687, 2020.

[5] M. B. N. Wajdi, I. Kuswandi, U. Al Faruq, Z. Zulhijra, K. Khairudin et al., "Education policy overcome coronavirus, a study of indonesians," EDUTEC: Journal of Education and Technology, vol. 3, no. 2, pp. 96-106, 2020.

[6] G. Basilaia and D. Kvavadze, "Transition to online education in schools during a SARS-CoV-2 coronavirus (COVID-19) pandemic in Georgia," Pedagogical Research, vol. 5, no. 4, pp. 1-9, 2020.

[7] M. L. Cheok and S. L. Wong, "Frog virtual learning environment for Malaysian schools: Exploring teachers experience," in ICT in Education in Global Context. Singapore: Springer, pp. 201-209, 2016.

[8] M. Ahmad, J. Badusah, A. Z. Mansor, A. Abdul Karim and F. Khalid, "The application of 21st century ICT literacy model among teacher trainees," Turkish Online Journal of Educational Technology, vol. 15, no. 3, pp. 151-161, 2016.

[9] N. A. Razak, H. M. Alakrash and Y. Sahboun, "English language teachers' readiness for the application of technology towards fourth industrial revolution demands," Asia-Pacific Journal of Information Technology and Multimedia, vol. 7, no. 2, pp. 89-98, 2018.

[10] M. Teräs, J. Suoranta, H. Teräs and M. Curcher, "Post-Covid-19 education and education technology 'solutionism': A seller's market," Postdigital Science and Education, vol. 1, no. 16, pp. 368-878, 2020. 
[11] L. Sun, Y. Tang and W. Zuo, "Coronavirus pushes education online," Nature Materials, vol. 9, no. 6, pp. 687, 2020.

[12] A. A. Azlan, M. R. Hamzah, T. J. Sern, S. H. Ayub and E. Mohamad, "Public knowledge, attitudes and practices towards COVID-19: A cross-sectional study in Malaysia," PLOS ONE, vol. 15, no. 5, pp. $1-15,2020$.

[13] A. Oke and F. A. P. Fernandes, "Innovations in teaching and learning: Exploring the perceptions of the education sector on the 4th industrial revolution (4IR)," Journal of Open Innovation: Technology, Market, and Complexity, vol. 6, no. 2, pp. 31-64, 2020.

[14] J. D. Basham, K. Han, L. Zhang and S. Yang, "Considering the fourth industrial revolution in the preparation" in Careers for Students with Special Educational Needs: Perspectives on Development and Transitions from the Asia-Pacific Region. Singapore: Springer, pp. 31-64, 2020.

[15] B. Yusuf and A. H. B. Nur, "Pedagogical orientation in the fourth industrial revolution: Flipped classroom model," in Redesigning Higher Education Initiatives for Industry 4.0. Pennsylvania, USA: IGI Global, pp. 85-104, 2019.

[16] E. L. Low, "English language teacher education for multilingual Singapore: Responding to the fourth industrial revolution," in Multilingual Education Yearbook. Berlin, Germany: Springer, pp. 129-148, 2020.

[17] N. A. Razak, M. Saeed and Z. Ahmad, "Adopting social networking sites (SNSs) as interactive communities among English foreign language (EFL) learners in writing: Opportunities and challenges," English Language Teaching, vol. 6, no. 11, pp. 187-198, 2013.

[18] H. M. Alakrash and N. A. Razak, "Towards the education 4. 0, readiness level of EFL students in utilizing technology-enhanced classroom," International Journal of Innovation, Creativity and Change, vol. 13, no. 10, pp. 161-182, 2020.

[19] A. Hamat, H. A. Hassan and M. A. Embi, "Collaboration and community of practice in online social networking services among Malaysian University students," Asean Journal of Teaching and Learning in Higher Education, vol. 11, no. 1, pp. 1-34, 2019.

[20] H. Alakrash, N. A. Razak and P. Krish, "Social network sites in learning English; An investigation on attitudes, digital literacy and usage," Linguistica Antverpiensia, vol. 1, pp. 26-43, 2021.

[21] A. Hamat and H. A. Hassan, "Use of social media for informal language learning by Malaysian University students," 3L: Language, Linguistics, Literature®, vol. 25, no. 4, pp. 68-83, 2019.

[22] P. Klarner, M. Sarstedt, M. Hoeck and C. Ringle, "Disentangling the effects of team competences, team adaptability, and client communication on the performance of management consulting teams," Long Range Planning, vol. 6, no. 3, pp. 258-286, 2018.

[23] R. Drath and A. Horch, "Industrie 4.0: Hit or hype?," IEEE Industrial Electronics Magazine, vol. 8, no. 2, pp. 56-58, 2014.

[24] H. Haron, S. Hussin, A. R. M. Yusof, A. Azmer, H. Samad et al., "Technology acceptance of MOOC among students at Public University: A conceptual framework," Asian Journal of Research in Education and Social Sciences, vol. 1, no. 2, pp. 27-32, 2019.

[25] A. A. Yassi, N. A. Razak and T. N. R. T. M. Maasum, "Integrated model for teaching language skills," International Journal of English Linguistics, vol. 9, no. 5, pp. 89-97, 2019.

[26] A. Hamouda, "The effect of virtual classes on Saudi EFL students' speaking skills," International Journal of Linguistics, Literature and Translation, vol. 3, no. 4, pp. 175-204, 2020.

[27] L. Canals and A. Al-Rawashdeh, "Teacher training and teachers' attitudes towards educational technology in the deployment of online English language courses in Jordan," Computer Assisted Language Learning, vol. 32, no. 7, pp. 639-664, 2019.

[28] A. S. Alqahtani, "The use of edmodo: Its impact on learning and students' attitudes toward it," Journal of Information Technology Education, vol. 18, pp. 319-330, 2019. 
[29] M. J. Gharehbagh, S. H. Stapa and S. Darus, "The effects of written corrective feedback using wikis among ESL learners," 3L: Language, Linguistics, Literature, vol. 25, no. 1, pp. 1-10, 2019.

[30] A. Omar, Z. Amir and M. Mohamad, "Facilitating online learning: Students' online discussion strategies for a project work at a technical university in Malaysia," 3L: Language, Linguistics, Literature ${ }^{\circledR}$, vol. 24, no. 4, pp. 102-114, 2018. 